\title{
Differential role of actin in lung endothelial and epithelial barrier properties in perfused rabbit lungs
}

\author{
L. Ermert*+, R. Rössig*, T. Hansen*, H. Schütte*, K. Aktories**, W. Seeger*
}

\begin{abstract}
Differential role of actin in lung endothelial and epithelial barrier properties in perfused rabbit lungs. L. Ermert, R. Rössig, T. Hansen, H. Schütte, K. Aktories, W. Seeger. CERS Journals Ltd 1996.

ABSTRACT: Lung fluid balance is critically dependent on capillary endothelial and alveolar epithelial barrier properties, and cytoskeletal components have been implicated in these barrier functions. In an earlier study, we perfused Clostridium botulinum $\mathrm{C}_{2}$ toxin, which effects selective loss of non-muscle $\mathbf{F}$-actin, through isolated rabbit lungs: a severalfold increase in the capillary filtration coefficient $(\mathrm{Kfc})$ was noted, together with attenuations and disruptions of endothelial cells upon electron microscopic examination. In this model we have investigated the influence of the $\mathrm{C}_{2}$ toxin on alveolar epithelial barrier properties. Epithelial permeability was assessed by continuous monitoring of the transepithelial passage of technetiumlabelled diethylenetriamine penta-acetic acid (99mTc-DTPA), offered to the alveolar surface by aerosol technique.

Intravascular administration of hydrogen peroxide, used as control agent, was shown to provoke a four- to fivefold increase in the clearance rate of ${ }^{99} \mathrm{~m}$ Tc-DTPA under conditions of severe fluid leakage into the lung interstitial and alveolar space. Intravascular administration of $\mathrm{C}_{2}$ toxin caused a dose- and time-dependent increase in $K f \mathrm{fc}$ values (8-15 fold), but the Tc-DTPA clearance rate was entirely unaffected. Moreover, transbronchial application of $\mathrm{C}_{2}$ toxin again reproduced the manifold increase in $K f \mathrm{f}$ data (about six fold), but the rate of transepithelial passage of the hydrophilic Tc-DTPA complex remained unchanged.

We conclude that the barrier properties of the lung microvascular endothelial and epithelial layer are differentially regulated. It is suggested that the actin microfilament system plays a decisive role in the structural and functional integrity of the endothelial but not the epithelial barrier.
\end{abstract}

Eur Respir J., 1996, 9, 93-99.

\begin{abstract}
*Dept of Internal Medicine and +Institute of Anatomy and Cytobiology, Justus-Liebig University Giessen, Giessen, Germany. **Institute of Pharmacology and Toxicology, University of the Saarland, Homburg, Germany.
\end{abstract}

Correspondence: W. Seeger Justus Liebig University Giessen Dept of Internal Medicine

Klinikstrasse 36

D-35385 Giessen

Germany

Keywords: Botulinum $\mathrm{C}_{2}$ toxin endothelial permeability epithelial permeability isolated rabbit lung

Received: December 281994 Accepted after revision August 151995

This work was supported by the Deutsche Forschungsgemeinschaft (SFB 249).
Lung oedema formation may be caused by two basically different mechanisms: increased fluid filtration under conditions of elevated capillary pressure (hydrostatic oedema); and transudation of fluid due to inflammatory or toxic deterioration of capillary endothelial and/or alveolar epithelial barrier function (high permeability pulmonary oedema) $[1,2]$. A combination of both mechanisms may also exist. Recent studies into the ultrastructural damage of the gas exchange area in rabbit lungs after exposure to high capillary pressures revealed disruptions of both endothelial and epithelial layers in variable association with additional rupture of the basement membrane [3-8]. These barrier lesions have been attributed to stress failure. The mechanisms maintaining cellular integrity and anchorage of cell-cell and cellmatrix contacts are overridden by the mechanical forces. Major importance for the maintenance of the endothelial and epithelial barrier function is attributed to the cytoskeleton, in particular actin filament stress fibres [9-11].

Interestingly, alterations reminiscent of stress failure lesions were recently noted in response to intravascular challenge of rabbit lungs with Clostridium botulinum $\mathrm{C}_{2}$ toxin at low capillary pressures [12]. $\mathrm{C}_{2}$ is a binary toxin, consisting of the two components $\mathrm{C}_{2 \mathrm{II}}$ and $\mathrm{C}_{2 \mathrm{II}}$ [13]. $\mathrm{C}_{2 \mathrm{II}}(\mathrm{Mr} 100,000)$ promotes the translocation of component I into eukaryotic cells. $\mathrm{C}_{2 \mathrm{I}}(\mathrm{Mr} 50,000)$ selectively adenosine diphosphate (ADP)-ribosylates non-muscle G-actin at arginine 177 [13, 14]. The covalent G-actin modification leads to a drastic inhibition of G-actin polymerization [13], and inhibits nucleation of polymerization by the gelsolin-actin complex [15]. In addition, $\mathrm{G}$-actin is converted into a capping protein, which binds to the barbed end of actin filaments and, thereby, inhibits the polymerization at this site, whereas the depolymerization at the pointed end is not affected. The net effect is the progressive and virtually complete decay of Factin [14]. In $\mathrm{C}_{2}$ toxin-treated perfused rabbit lungs, a severalfold increase in the capillary filtration coefficient $(K \mathrm{fc})$ was noted, accompanied by extensive oedema formation, and electron microscopic examination of these lungs revealed attenuations and disruptions of endothelial cells [12]. $\mathrm{C}_{2}$ toxin effects were partly antagonized by the F-actin stabilizing agent phallacidin. These findings 
strongly support an important role of the actin microfilament system for the structural and functional integrity of the lung capillary endothelial layer at physiological vascular pressures.

The present study was undertaken to probe the role of the actin-based filamentous network for the alveolar epithelial barrier function in intact rabbit lungs. Continuous monitoring of the transepithelial passage of aerosolized $99 \mathrm{~m}$ technetium-labelled diethylenetriamine penta-acetic acid (99mTc-DTPA) MW 492 Da was used for assessment of these barrier properties, and botulinum $\mathrm{C}_{2}$ toxin - offered to both the endothelial and epithelial surface - was again employed for selective perturbation of actin. Both methods of toxin delivery again provoked capillary endothelial leakage, whereas the transepithelial tracer passage remained entirely unaffected. These results suggest a differential role of the actin microfilament system in capillary endothelial and alveolar epithelial barrier properties in intact lungs.

\section{Methods}

\section{Reagents}

Hydroxyethylamylopectin (MW 200,000) was received from Fresenius AG (Oberursel, Germany), $\mathrm{CaNa}_{3}$-DTPA/ $\mathrm{SnCl}_{2}-2 \mathrm{H}_{2} \mathrm{O}$ from Amersham Buchler (Braunschweig, Germany), and ${ }^{99} \mathrm{mcO}_{4}{ }^{-}$was graciously supplied by G.L. Fängewisch, Dept of Nuclear Medicine, Giessen. All other chemicals were obtained from Merck (Darmstadt, Germany).

\section{Preparation of $C_{2}$ toxin}

Preparation of the components I and II of the toxin was performed essentially as described previously [16]. Aliquots of one batch of each toxin component, dissolved in saline, were stored at $-20^{\circ} \mathrm{C}$ and used throughout the study. Mixing of the components was performed directly before experimental use. Saline served as control substance for sham injections.

\section{Isolated lung model}

The model has been described previously [17]. Briefly, rabbits of either sex (body weight (BW) 2.2-2.6 kg) were deeply anaesthetized and anticoagulated with heparin, $1,000 \mathrm{U} \cdot \mathrm{kg}^{-1} \mathrm{BW}$. The lungs were removed with trachea and bronchi attached, whilst being perfused with Krebs-Henseleit buffer through cannulae in the pulmonary artery and the left atrium. The buffer contained $132.8 \mathrm{mM} \mathrm{NaCl}, 4.3 \mathrm{mM} \mathrm{KCl}, 1.1 \mathrm{mM} \mathrm{KH} \mathrm{PO}_{4}, 24.1$ $\mathrm{mM} \mathrm{NaHCO} 3,2.4 \mathrm{mM} \mathrm{CaCl}_{2}$ and $1.3 \mathrm{mM} \mathrm{MgPO}_{4}$, as well as $240 \mathrm{mg}$ glucose and $5 \mathrm{~g}$ hydroxyethylamylopectin (as oncotic agent) per $100 \mathrm{~mL}$. The lungs were placed in a temperature-equilibrated housing chamber at $37^{\circ} \mathrm{C}$, freely suspended from a force transducer. They were ventilated via the trachea with $4 \% \mathrm{CO}_{2}, 17 \% \mathrm{O}_{2}$ and $\mathrm{N}_{2}$ (tidal volume $30 \mathrm{~mL}$; frequency 30 ventilations $\cdot \mathrm{min}^{-1}$; end-expiratory pressure $1 \mathrm{cmH}_{2} \mathrm{O}$ ), the $\mathrm{pH}$ of the perfusion fluid ranged 7.35-7.45. After extensive rinsing of the vascular bed, the lungs were perfused with a pulsatile flow of $150 \mathrm{~mL} \cdot \mathrm{min}^{-1}$. Perfusion fluid was recirculated but the alternate use of two separate perfusion circuits, each containing $200 \mathrm{~mL}$, allowed exchange of perfusion fluid. Perfusion pressure, ventilation pressure and the weight of the isolated organ were registered continuously. The left atrial pressure was set to $2 \mathrm{mmHg}$ under baseline conditions ( 0 referenced at the hilum) to guarantee zone III conditions at end-expiration throughout the lung. The capillary filtration coefficient $(K \mathrm{fc}$, given in $\mathrm{cm}^{3} \cdot \mathrm{s}^{-1} \cdot \mathrm{mmHg}^{-1} \cdot \mathrm{g}^{-1}$ wet lung weight $\times 10^{-4}$ ) and the total vascular compliance were determined gravimetrically from the slope induced by a $7.5 \mathrm{mmHg}$ step elevation of the venous pressure for $8 \mathrm{~min}$. The application of this method to the present model and the use of zero time extrapolation of the slope of weight gain for the calculation of $K \mathrm{fc}$ have been described previously [17]. In lungs already displaying toxin-induced weight gain before onset of the hydrostatic challenge, the pressure step-induced rate of weight gain was corrected for this baseline rate of weight gain. In addition, the hydrostatic challenge-induced net increase in lung weight $(\Delta \mathrm{W}$, determined as the difference between prechallenge and 2 min post-challenge weight) was assessed. Lungs selected for the study were those that: 1) had a homogenous white appearance without signs of haemostasis or oedema formation; 2) had pulmonary artery and ventilation pressure in the normal range; and 3) were isogravimetric during a steady-state period of $40 \mathrm{~min}$.

\section{Measurement of clearance rate of inhaled aerosolized ${ }^{99 m}$ Tc-DTPA}

The clearance rate of aerosolized ${ }^{99 m T c-D T P A ~ f r o m ~}$ the lungs into the perfusion fluid was used as an index of pulmonary epithelial permeability [18-20].

Aerosol preparation and evaluation. $\mathrm{CaNa}_{3}$-DTPA, 1.2 $\mathrm{mg}$, and $\mathrm{SnCl}_{2}-2 \mathrm{H}_{2} \mathrm{O}, 0.016 \mathrm{mg}$, were added to $0.5 \mathrm{~mL}$ of sterile saline in a reaction vial, followed by $270 \mu \mathrm{Ci}$ of $99 \mathrm{~m}^{-} \mathrm{TcO}_{4}^{-}$in $0.5 \mathrm{~mL}$ of saline, incubated for $20 \mathrm{~min}$. This solution was placed in a Savac nebulizer, driven with the same gas mixture as used for lung ventilation, at a pressure of 12 Psi. To minimize dissociation of the 99mTc-DTPA complex, the radiopharmaceutical was prepared within 20 min of use. Repetitive analysis of the degree of binding between ${ }^{99 \mathrm{mTc}}$ and DTPA was performed by paper chromatography in samples collected from the residual fluid in the nebulizer and collected from the lung perfusion circuit up to $120 \mathrm{~min}$ after aerosol administration. Chromatography was performed in duplicate on strips $1.0 \times 10 \mathrm{~cm}$ of Whatman No. 3 paper as described previously [21]; the binding surpassed $99 \%$ in all cases. Size of the aerosol particles was determined by a differential mobility analyser (DMA), connected to a condensation nucleus counter (CNC) (kindly performed by J. Gebhart, GSF, Frankfurt, Germany). The mass median aerodynamic diameter (MMAD) of the particles 
was $1.1 \mu \mathrm{M}$, with a geometric standard deviation (GSD) of 2.1. The aerosol was delivered to the inspiration loop of the ventilator by use of a bag-in-box system; approximately $4-5 \mu \mathrm{Ci}$ 99m $\mathrm{Tc}$ were deposited in the lung bronchoalveolar compartment within 6-10 min by use of this technique.

Data collection and calculation of clearance rate. Two 2 inch sodium-iodide detectors, connected with a Ramona G gamma counter (Raytest, Straubenhardt, Germany), were levelled to the costal side of the left lung at a distance of $3 \mathrm{~cm}$ to the tracheal bifurcation and to the perfusion circuit reservoir [22]. Lung and perfusate reservoir were shielded by lead from each other and from background activity. This equipment summed the number of counts every second; averaging was performed every 30 s. Absolute counts were corrected for the radioactive half-life of $99 \mathrm{mTc}$ (360 min) and for the difference in recoveries of tracer between lung and perfusate sampling position. The latter were assessed by separating the lung and the perfusion circuit and independently loading both with known quantities of tracer. Correction for perfusateassociated radioactivity contained in the lung vascular volume $(\sim 3 \mathrm{ml})$ was not undertaken, as this never surpassed $0.5 \%$ of total lung radioactivity (due to the large perfusate reservoir into which the tracer was diluted after transepithelial passage). Kinetics of lung and perfusate radioactivity were displayed, and the 99mTc-DTPA clearance rate was calculated as fractional decrease of lungassociated radioactivity per $\min \left(-\% \cdot \mathrm{min}^{-1}\right)$.

\section{Experimental design}

After termination of the initial steady-state period, the recirculating Krebs-Henseleit hydroxyethylamylopectin buffer was exchanged with fresh buffer medium, preloading of the lungs with 99mTc-DTPA was performed and baseline clearance rate was measured for a $15 \mathrm{~min}$ period (range -0.4 to $-1.6 \%$ in all experiments). Next, time was set to zero and $\mathrm{C}_{2}$ toxin, $\mathrm{H}_{2} \mathrm{O}_{2}$ or sham challenge was undertaken. Toxin doses were chosen according to dosage used in the preceding study with intravascular application of $\mathrm{C}_{2}$ toxin in isolated rabbit lungs [12]. Whilst radioactivity was monitored continuously, hydrostatic challenges for assessment of $K \mathrm{fc}$ were performed 20, 50 and 80 min after application of stimulus. Perfusion was terminated 2 min after finishing the third venous pressure elevation, or when the toxin-induced increase in lung weight gain $(\Delta \mathrm{W})$ surpassed $30 \mathrm{~g}$. Six experimental groups were studied, each with five isolated lungs: Control. Sham application of $500 \mu \mathrm{l}$ saline, either injected into the pulmonary artery $(n=2)$ or applied intratracheally $(n=3)$.

$C_{2} 0.06 / 0.12 \mu g$ infus. $\mathrm{C}_{2 \mathrm{I}}(0.06 \mu \mathrm{g})$ and $\mathrm{C}_{2 \mathrm{II}}(0.12 \mu \mathrm{g})$ were premixed in $500 \mu \mathrm{L}$ saline and infused into the pulmonary artery within $2 \mathrm{~min}$.

$C_{2} 1 / 2 \mu g$ infus. $\mathrm{C}_{2 \mathrm{I}}(1 \mu \mathrm{g})$ and $\mathrm{C}_{2 \mathrm{II}}(2 \mu \mathrm{g})$ were premixed in $500 \mu \mathrm{L}$ saline and infused into the pulmonary artery within $2 \mathrm{~min}$.
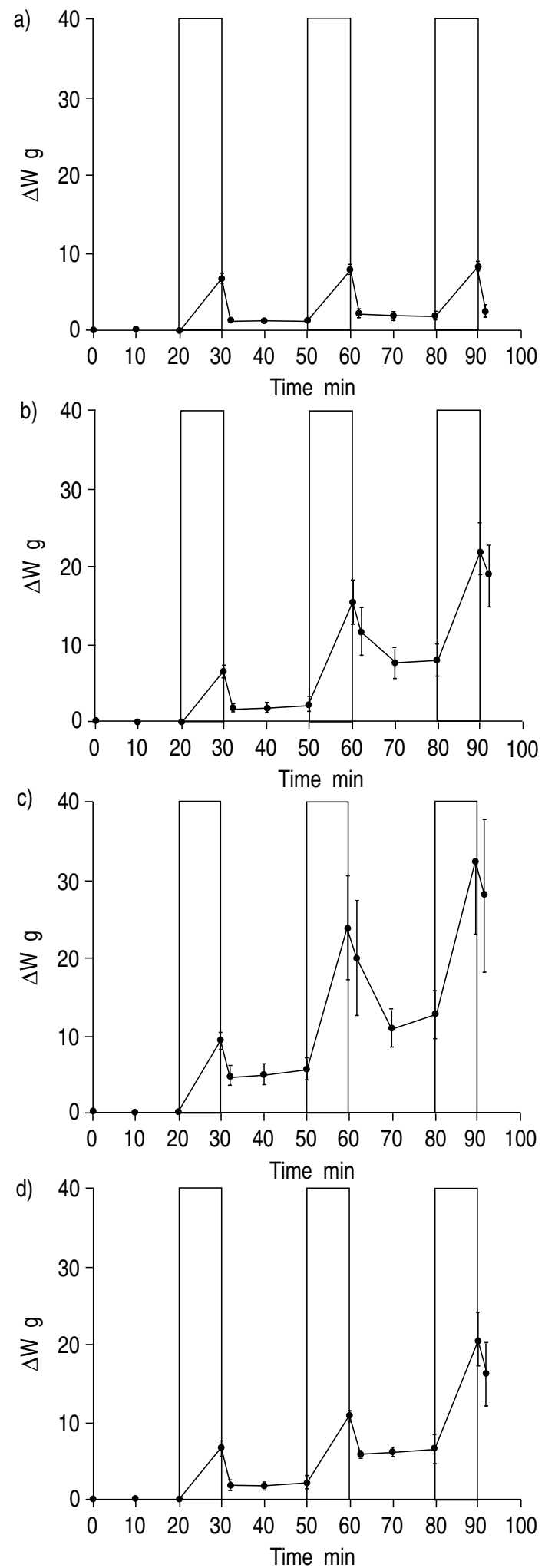

Fig. 1. - Time-course of lung weight gain $(\Delta \mathrm{W})$ : a) in control lungs; and $b-d$ ) in lungs exposed to different $C_{2}$ toxin doses (b) $C_{2} 1 / 2 \mu g$ intravascular infusion; c) $\mathrm{C}_{2} 2 / 4 \mu \mathrm{g}$ intravascular infusion; d) $\mathrm{C}_{2} 2 / 4$ $\mu \mathrm{g}$ via trachea). The $10 \mathrm{~min}$ hydrostatic challenges $(20,50$ and 80 min) are indicated by columns. Mean values \pm SEM of five experiments each are depicted (SEM bars are missing when falling into symbol). Except for the low-dose toxin group $(0.06 / 0.12 \mu \mathrm{g}$; not depicted as not differing from the control group), all groups with botulinum $\mathrm{C}_{2}$ toxin application were significantly different from the control group. 
$C_{2} 2 / 4 \mu g$ infus. $\mathrm{C}_{2 \mathrm{I}}(2 \mu \mathrm{g})$ and $\mathrm{C}_{2 \mathrm{II}}(4 \mu \mathrm{g})$ were premixed in $500 \mu \mathrm{L}$ saline and infused into the pulmonary artery within 2 min.

$C_{2} 2 / 4 \mu g$ trach. $\mathrm{C}_{2 \mathrm{I}}(2 \mu \mathrm{g})$ and $\mathrm{C}_{2 \mathrm{II}}(4 \mu \mathrm{g})$ were premixed in $500 \mu \mathrm{L}$ saline and slowly injected into the trachea via a small catheter whilst rotating the lung.

$\mathrm{H}_{2} \mathrm{O}_{2}$. This agent was admixed to the recirculating buffer fluid at a final concentration of $250 \mu \mathrm{M}$. In order to avoid a large increase in pulmonary artery pressure, the application of $\mathrm{H}_{2} \mathrm{O}_{2}$ was performed in the presence of

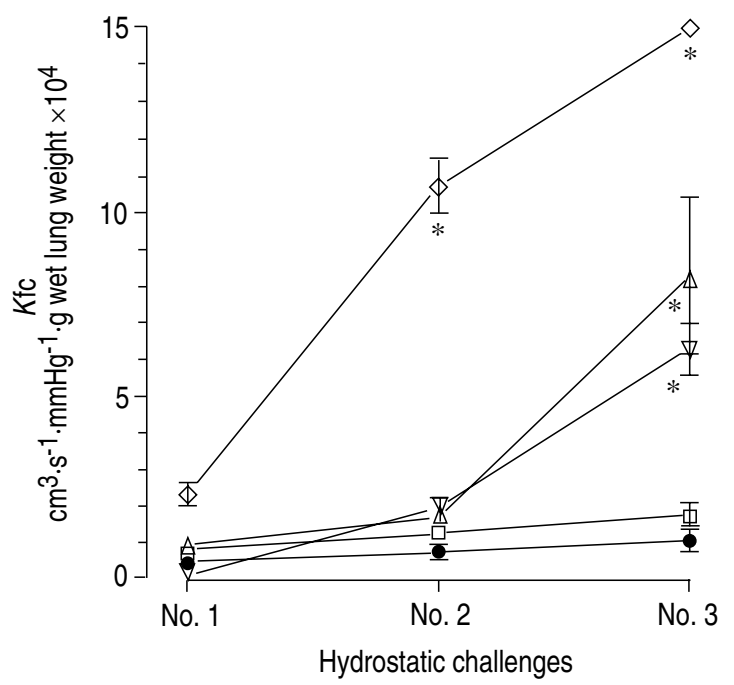

Fig. 2. - Time- and dose-dependent increase in the capillary filtration coefficient $(K \mathrm{fc})$ in response to botulinum $\mathrm{C}_{2}$ toxin stimulation. Hydrostatic challenges were performed $20 \mathrm{~min}$ (No. 1), $50 \mathrm{~min}$ (No. 2) and $80 \mathrm{~min}$ (No. 3) after toxin application. Mean values \pm SEM of five experiments each are depicted (SEM bars are missing when falling into symbol). After 80 min (challenge No. 3) all groups with botulinium $\mathrm{C}_{2}$ toxin application differed significantly from the control group, except for the low-dose toxin group $(0.06 / 0.12 \mathrm{\mu g}$. *: $\mathrm{p}<0.05 . \longrightarrow$ : $\mathrm{C}_{2} 2 / 4 \mu \mathrm{g}$ infus.; $-\Delta-\mathrm{C}_{2} 1 / 2 \mu \mathrm{g}$ infus.; $-\nabla-: \mathrm{C}_{2} 2 / 4 \mu \mathrm{g}$ trach.; $\longrightarrow: \mathrm{C}_{2} 0.06 / 0.12 \mu \mathrm{g}$ infus. $\multimap$ : control.

a)

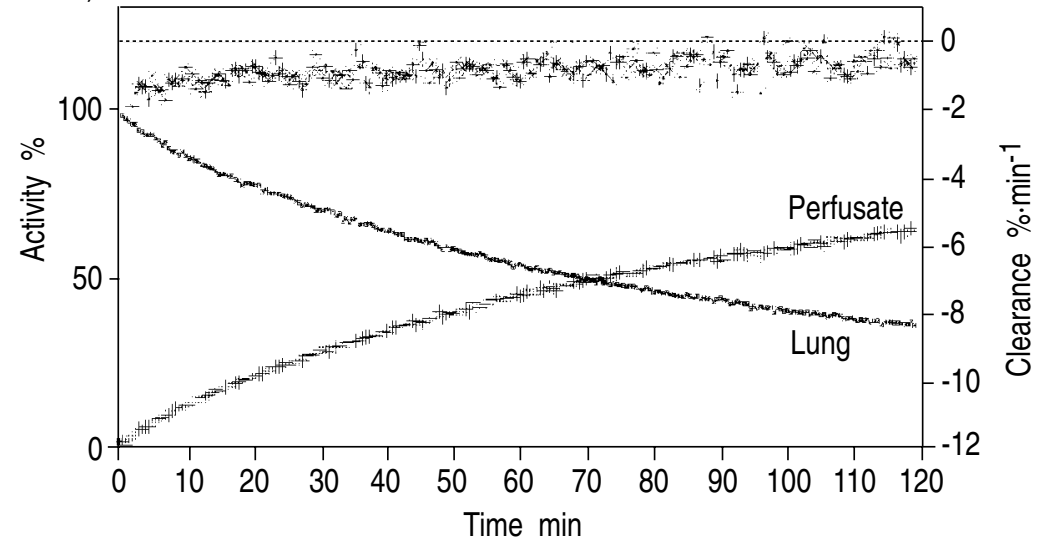

$500 \mu \mathrm{M}$ acetylsalicylic acid. Statistics

All values are given as mean \pm SEM. For assessment of statistical significance, two-way analysis of variance was performed; significance was assumed when the p-value was less than 0.05 .

\section{Results}

\section{Pulmonary artery pressure}

In all lungs, the pulmonary artery pressure ranged 5$8 \mathrm{mmHg}$ during the initial baseline period. In all groups vascular compliance did not change. Neither intravascular nor intratracheal challenge with botulinum $\mathrm{C}_{2}$ toxin provoked any change in vascular perfusion pressure throughout the experiments. Due to the presence of acetylsalicylic acid, the $\mathrm{H}_{2} \mathrm{O}_{2}$-provoked increase in pulmonary artery pressure (which is known to be largely thromboxane mediated in rabbit lungs [23]) was restricted to $<3 \mathrm{mmHg}$.

\section{Endothelial permeability and lung weight gain}

In control lungs and in lungs subjected to the low $\mathrm{C}_{2}$ toxin dose of $0.06 / 0.12 \mu \mathrm{g}$, no spontaneous weight gain occurred (fig. 1), and the $K \mathrm{fc}$ values never surpassed 2.5 $\mathrm{cm}^{3} \cdot \mathrm{s}^{-1} \cdot \mathrm{mmHg}^{-1} \cdot \mathrm{g}$ wet lung weight $\times 10^{-4}$ (fig. 2). The hydrostatic challenge-induced weight gain was largely reversible after termination of the manoeuvres of venous pressure elevation (fig. 1). In contrast, application of the combined components of botulinum $\mathrm{C}_{2}$ toxin at higher dosage (1/2 and $2 / 4 \mu \mathrm{g}$ infused into the circulation) caused a time- and dose-dependent, pronounced increase in $K \mathrm{fc}$ values (fig. 2). For the second challenge, lungs treated with $2 / 4 \mu \mathrm{g} \mathrm{C}_{2}$ toxin differed significantly $(\mathrm{p}<0.005)$ from control lungs. For the third challenge all groups with $\mathrm{C}_{2}$ toxin, except for the low-dose toxin group $(0.06 / 0.12)$, dif- b)

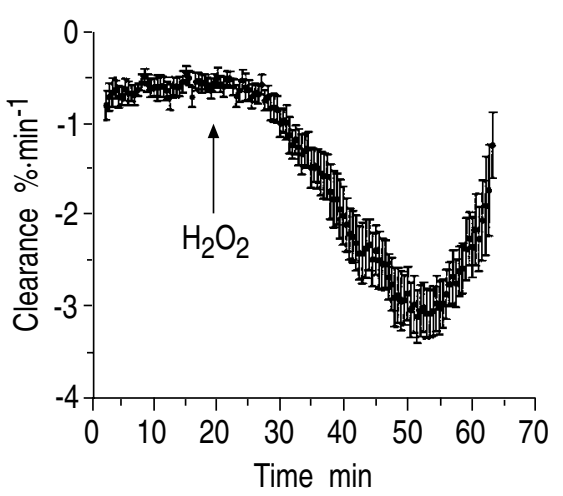

Fig. 3. - Time-course of lung 99mtechnetium-labelled diethylenetriamine penta-acetic acid (99mTc-DTPA) clearance: a) in control lungs; and b) in lungs exposed to $\mathrm{H}_{2} \mathrm{O}_{2}(250 \mu \mathrm{m})$. a) After termination of lung 99mTc-DTPA deposition, radioactivity tracing was started over the lung (set $100 \%$ ) and over the perfusate reservoir (starting point 0\%) (mean values of two separate experiments shown). Counts were corrected for the different recoveries of the two tracing positions and for the decay of label. Clearance rates $\left(-\% \cdot \mathrm{min}^{-1}\right)$ were calculated from the decline in lung radioactivity every $30 \mathrm{~s}$. The constancy of clearance rates in the two control lungs is evident. * : clearance rates; $\mathbf{0}:$ lung; +: perfusate. b) Marked increase in the $99 \mathrm{~m}$ Tc-DTPA clearance rate in lungs exposed to $\mathrm{H}_{2} \mathrm{O}_{2}(250 \mu \mathrm{m})$ challenge ( $\mathrm{n}=5$ experiments; mean \pm sEM bars given for each time-point). 

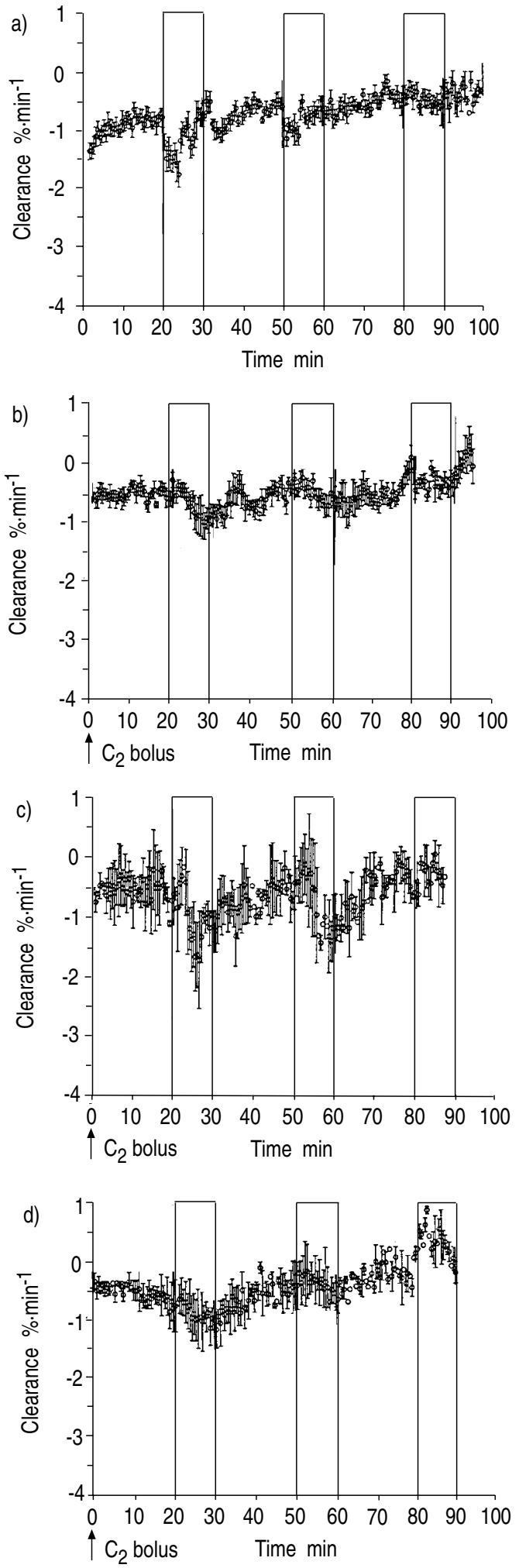

Fig. 4. - Time-course of lung 99mtechnetium-labelled diethylenetriamine penta-acetic acid ( $99 \mathrm{mTc}-\mathrm{DTPA})$ clearance: a) in control lungs $(\mathrm{n}=5)$; and $\mathrm{b}-\mathrm{d})$ in lungs exposed to different doses of botulinum $\mathrm{C}_{2 \mathrm{I} / \mathrm{II}}$ ( $\mathrm{n}=5$ each; b) $\mathrm{C}_{2} 1 / 2 \mu \mathrm{g}$ infus.; c) $\mathrm{C}_{2} 2 / 4 \mu \mathrm{g}$ infus.; d) $\mathrm{C}_{2} 2 / 4 \mu \mathrm{g}$ trach.) Clearance rates were calculated every $30 \mathrm{~s}$ (mean \pm sEM bars given for each time-point). The hydrostatic challenges (at 20,50 and $80 \mathrm{~min}$ ) are indicated by shaded vertical bars. None of the groups with toxin application differed from the control group. infus.: infused intravascularly; trach.: applied transtracheally. fered significantly from the control group $(\mathrm{p}<0.05)$. There was a concomittant marked lung weight gain associated with $\mathrm{C}_{2}$ toxin (fig. 1). A corresponding severe loss of endothelial barrier function was also noted upon intratracheal administration of the botulinum toxin. Interestingly, $2 / 4 \mu \mathrm{g} \mathrm{C}_{2}$ toxin applied via the transbronchial route virtually completely matched the extent and kinetics of $K \mathrm{fc}$ increase (>fivefold; fig. 2) and weight gain (up to $20 \mathrm{~g}$; fig. 1) in response to intravascular application of $1 / 2 \mu \mathrm{g}$ toxin.

\section{Epithelial permeability}

Subsequent to $99 \mathrm{~m}$ Tc-DTPA aerosol administration, a monoexponential decrease of lung-associated radioactivity, paralleled by a countercurrent increase in perfusate counts, was noted in all control lungs (figs. 3a and 4a). The calculated DTPA clearance rate ranged $0.4-1.6 \%$. $\mathrm{min}^{-1}$, in accordance with previously published data for human and rabbit lungs [19]; it did not change over the entire observation period of $90 \mathrm{~min}$ in all control experiments (figs. 3 and 4a). Intravascular administration of $\mathrm{H}_{2} \mathrm{O}_{2}$ provoked protracted lung oedema formation (30 g weight gain within 55-65 min in all lungs; data not given in detail); and it also provoked a rapid, severalfold increase in the $99 \mathrm{mTc}$-DTPA clearance rate up to 4-5 fold values (fig. $3 \mathrm{~b}$ ). In contrast, neither intravascular nor transtracheal application of botulinum toxin evoked any significant increase in the clearance rate of 99mTc-DTPA (fig. 4). The only change was some increased scattering of values during the hydrostatic challenges in the lungs with extensive oedema formation $(2 / 4 \mu \mathrm{g}$ toxin applied intravascularly; fig. 4c), which did not affect the overall kinetics of transepithelial $99 \mathrm{mTc}-\mathrm{DTPA}$ passage.

\section{Discussion}

In the present study, botulinum $\mathrm{C}_{2}$ toxin was used as a tool for selective perturbation of non-muscle F-actin. The effect of botulinum $\mathrm{C}_{2}$ toxin on endothelial cell monolayers and human neutrophils is characterized by a time- and dose-dependent increase of G-actin and a decrease of F-actin [24, 25]. The kinetics of F-actin loss was compatible with the increase in hydraulic conductivity in the endothelial cell monolayer study [24]. As reported previously, intravascular administration of this agent in the isolated lung model provoked a dose-dependent, dramatic increase in the capillary filtration coefficient, concomitant with severe lung oedema formation, both under baseline conditions and, in particular, in response to hydrostatic challenges [12].

Preloading of lung cells in the isolated perfused lung model with phallacidin, which in opposition to $\mathrm{C}_{2}$ toxin decreases F-actin depolymerization, significantly reduced the $\mathrm{C}_{2}$ toxin-induced increase in vascular permeability after intravascular application of $\mathrm{C}_{2}$ toxin [12]. As the vascular pressures were entirely unaffected, being comparable in control lungs and $\mathrm{C}_{2}$-treated lungs, and vascular compliance did not change (data not given in detail), there was no evidence for any substantial in- 
crease in endothelial surface area, and the dramatic rise in $K \mathrm{fc}$ and lung weight must be fully ascribed to an increase in the hydraulic conductivity of the lung endothelial barrier. Moreover, the extent of $K \mathrm{fc}$ rise and fluid accumulation strongly suggests that the lung microvasculature represents the predominant site of toxin attack, as it is by far the leading site of lung fluid filtration [26, 27], and the presently observed severalfold increase in hydraulic conductivity is not imaginable without major involvement of this capillary filtration site. This view is fully supported by the electron microscopic examination of $\mathrm{C}_{2}$ toxin-treated lungs, showing attenuations and disruptions of endothelial cells throughout the capillary bed [12].

In these preceding studies, no gross morphological deterioration of alveolar epithelial cells type I was noted [12], and the current study directly focused on the permeability characteristics of this barrier. We employed continuous monitoring of the transepithelial passage of 99mTc-DTPA, offered to the alveolar surface by aerosol technique, as the clearance of this hydrophilic complex is a sensitive marker of alveolar epithelial barrier function in intact lungs [18-20]. The rate-limiting step of its escape from the alveolar surface into the perfusate is the diffusion via interepithelial clefts, whereas the subsequent transendothelial passage is much less restricted. The constancy of the continuously calculated clearance rate of Tc-DTPA over the entire experimental period was demonstrated in control lungs.

To probe the reliability of this technique to also assess increase in epithelial permeability under conditions of severe fluid leakage into the interstitial and alveolar spaces, we employed $\mathrm{H}_{2} \mathrm{O}_{2}$ challenge as a "positive" control group. This agent is a potent inductor of a variety of second messenger events in alveolar epithelial cells, including elevation of intracellular calcium [28]; and the latter signal may be related to contractile events with intercellular gap formation, as described for endothelial monolayers [29]. In the current perfused lung model, $\mathrm{H}_{2} \mathrm{O}_{2}$ elicited a rapid, manifold increase in the Tc-DTPA clearance in the presence of lung fluid accumulation, the extent and kinetics of which were comparable to the oedema formation in the lungs with highest $\mathrm{C}_{2}$ toxin challenge.

In contrast to $\mathrm{H}_{2} \mathrm{O}_{2}$ stimulation, intravascular administration of botulinum $\mathrm{C}_{2}$ toxin did not provoke any rise in Tc-DTPA clearance up to the highest concentration used [12]. One possible explanation might be a compartmental effect: due to admixture to the vascular compartment, sufficiently high concentrations might reach the endothelial, but not the epithelial cells. This interpretation was, however, questioned by the previous finding that intravascular $\mathrm{C}_{2}$ toxin application effected fusion of lamellar bodies with each other and the cell membrane in alveolar epithelial type II cells, which is compatible with loss of actin due to $\mathrm{C}_{2}$ toxin efficacy in this cell type. To probe any compartmental effect more directly, additional studies with transbronchial application of a high dose of botulinum toxin were performed. Interestingly, a severalfold increase in $K \mathrm{fc}$ values was again provoked, with approximately half efficacy of the transbronchially-applied, as compared to the intravascu- larly-administered, toxin dose. Significant access from the alveolar surface to the endothelial cells must, thus, be assumed, although it is presently unknown whether this proceeds via interepithelial diffusion of toxin molecules or via some transcellular passage by virtue of the membrane-translocating efficacy of the $\mathrm{C}_{2 \mathrm{II}}$ component of the botulinum toxin [13, 14]. Again, however, no increase in Tc-DTPA clearance was noted in response to the botulinum $\mathrm{C}_{2}$ toxin challenge.

These findings strongly suggest that the actin microfilament system does not play a decisive role in the structural integrity of alveolar epithelial cells, as is evidently the case in the capillary endothelial cells. The cytoskeleton is composed of three types of protein filament - actin filaments, microtubules and intermediate filaments which are each composed of different protein subunits [30]. The morphological organization of the cytoskeletal network differs between various cell types, and characteristic architectures of specialized intercellular contacts have been reported [31-35]. Intermediate filaments were found to be particularly prominent in cells exposed to tension forces, providing resistance against mechanical stress $[30,36]$. In epithelial cells, the intermediate filament system, forming an intracellular scaffold, may play a major role for cellular stability [36], with only a minor contribution of actin.

The results of the present study differ somewhat from previous investigations in ligated intestinal loops of mice, addressing the influence of intraluminally applied botulinum $\mathrm{C}_{2}$ toxin on the epithelial barrier characteristics [37]. In these studies, a rise in loop weight was noted, and assumed to indicate increased epithelial permeability. Either intestinal epithelial cells might differ from alveolar cells with respect to the role of actin in the maintenance of barrier properties, or some transepithelial penetration of $\mathrm{C}_{2}$ toxin with efficacy on vascular endothelial cells may underlie the findings of OHISHI et al. [37], in correspondence with the current observations.

In conclusion, botulinum $\mathrm{C}_{2}$ toxin possesses strong potency to provoke deterioration of capillary endothelial barrier function in intact lungs, independent of application via intravascular or transbronchial route. These findings indicate an important role for the actin microfilament system in the maintenance of structural and functional integrity of lung microvascular endothelial cells under physiological conditions. Moreover, alterations of the microfilament system could be the decisive step for the development of permeability changes due to a variety of inflammatory agents. In contrast, alveolar epithelial barrier properties are not affected by either route of $\mathrm{C}_{2}$ toxin application. These data suggest differential regulation of the permeability characteristics in these closely adjacent barriers with respect to actin. Non-actin components of the cytoskeleton appear to predominate in the alveolar epithelial cell type.

Acknowledgements: The authors are grateful to R.L. Snipes, Department of Anatomy, Giessen for linguistically 
reviewing the manuscript.

\section{References}

1. Crapo JD (Editorial). New concepts in the formation of pulmonary edema. Am Rev Respir Dis 1993; 147: 790-792.

2. Staub NC, Taylor CR. In: Edema. New York, Raven Press, 1984.

3. Elliott AR, Fu Z, Tsukimoto K, Prediletto R, MathieuCostello O, West JB. Short-term reversibility of ultrastructural changes in pulmonary capillaries caused by stress failure. J Appl Physiol 1992; 73: 1150-1158.

4. Tsukimoto K, Mathieu-Costello O, Prediletto R, Elliott AR, West JB. Ultrastructural appearances of pulmonary capillaries at high transmural pressures. J Appl Physiol 1991; 71: 573-582.

5. West JB, Tsukimoto K, Mathieu-Costello O, Prediletto R. Stress failure in pulmonary capillaries. J Appl Physiol 1991; 70: 1731-1742.

6. Costello ML, Mathieu-Costello O, West JB. Stress failure of alveolar epithelial cells studied by scanning electron microscopy. Am Rev Respir Dis 1992; 145: 1446-1455.

7. Bachofen H, Schürch S, Michel RP, Weibel ER. Experimental hydrostatic pulmonary edema in rabbit lungs: morphology. Am Rev Respir Dis 1993; 147: 989-996.

8. Bachofen H, Schürch S, Weibel ER. Experimental hydrostatic pulmonary edema in rabbit lungs: barrier lesions. Am Rev Respir Dis 1993; 147: 997-1004.

9. Drenckhahn D, Wagner J. Stress fibers in the splenic sinus endothelium in situ: molecular structure, relationship to the extracellular matrix and contractility. $J$ Cell Biol 1986; 102: 1738-1747.

10. Franke RP, Grafe M, Schnittler H, Seiffge D, Mittermayer $\mathrm{C}$, Drenckhahn D. Induction of human vascular endothelial stress fibers by fluid shear stress. Nature 1984; 307 : 648-649.

11. Wong AJ, Pollard TD, Herman IM. Actin filament stress fibers in vascular endothelial cells in vivo. Science 1983; 219: 867-869.

12. Ermert L, Brückner J, Walmrath D, et al. Role of endothelial cytoskeleton in high-permeability edema due to botulinum $\mathrm{C}_{2}$ toxin in perfused rabbit lungs. $A m \mathrm{~J}$ Physiol 1995; 268: L753-L761.

13. Aktories K, Wegner A. ADP-ribosylation of actin by Clostridial toxins. J Cell Biol 1989; 109: 1385-1387.

14. Wegner A, Aktories K. ADP-ribosylated actin caps the barbed ends of actin filaments. J Biol Chem 1988; 263: 13739-13742.

15. Wille M, Just I, Wegner A, Aktories K. ADP-ribosylation of gelsolin-actin complexes by clostridial toxins. J Biol Chem 1992; 267: 50-55.

16. Ohishi I, Iwasaki M, Sakaguchi G. Vascular permeability of botulinum $\mathrm{C}_{2}$ toxin elicited by co-operation of two dissimilar protein components. Infect Immun 1980; 31: 890-895.

17. Seeger W, Walmrath D, Menger M, Neuhof H. Increased lung vascular permeability after arachidonic acid and hydrostatic challenge. J Appl Physiol 1986; 61: 17811789.

18. Staub NC, Hyde RW, Crandall E. Workshop on techniques to evaluate lung alveolar-microvascular injury. Am Rev Respir Dis 1990; 141: 1071-1077.

19. Smith RJ, Hyde RW, Waldman DL, et al. Effect of pattern of aerosol inhalation on clearance of technetium ${ }^{99 \mathrm{~m}}$-labeled diethylenetriamine penta-acetic acid from the lung of normal humans. Am Rev Respir Dis 1992; 145: 1109-1116.

20. Wiener-Kronisch JP, Albertine KH, Matthay MA. Differential responses of the endothelial and epithelial barriers of the lung in sheep to Escherichia coli endotoxin. J Clin Invest 1991; 88: 864-875.

21. Waldmann DL, Weber DA, Oberdoerster G. Chemical breakdown of technetium ${ }^{99 \mathrm{~m}}$-DTPA during nebulization. J Nucl Med 1987; 28: 378-382.

22. Schütte H, Rosseau S, Walmrath D, Grimminger F, Ernst $\mathrm{Ch}$, Seeger W. Neutrophil passage through isolated perfused rabbit lungs. Am J Physiol 1991; 261: H1317H1323.

23. Seeger W, Suttorp N, Schmidt F, Neuhof H. The glutathione redox cycle as a defense system against hydrogen peroxide-induced prostanoid formation and vasoconstriction in rabbit lungs. Am Rev Respir Dis 1986; 133: 1029-1036.

24. Suttorp N, Polley M, Seybold J, et al. Adenosine diphosphate ribosylation of $\mathrm{G}$-actin by botulinum $\mathrm{C}_{2}$ toxin increases endothelial permeability in vitro. J Clin Invest 1991; 87: 1575-1584.

25. Grimminger F, Sibelius U, Aktories K, Just I, Seeger W. Suppression of cytoskeletal rearrangement in activated human neutrophils by botulinum $\mathrm{C}_{2}$ toxin. $\mathrm{J}$ Biol Chem 1991; 266: 19276-19282.

26. Fishman AP. Pulmonary edema. In: Fishman AP, eds. Pulmonary Diseases and Disorders. New York, McGrawHill, 1988; pp. 919-952.

27. Malik AB, Staub NC. Mechanism of lung microvascular injury. NY Acad Sci 1982.

28. Rice KL, Duane PG, Archer SL, Gilboe DP, Niewoehner DE. $\mathrm{H}_{2} \mathrm{O}_{2}$ injury causes $\mathrm{Ca}^{2+}$ dependent and independent hydrolysis of phosphatidylcholine in alveolar epithelial cells. Am J Physiol 1992; 263: L430-L438.

29. Suttorp N, Weber U, Welsch T, Schudt C. Role of phosphodiesterases in the regulation of endothelial permeability in vitro. J Clin Invest 1993; 91: 1421-1428.

30. Alberts B, Bray D, Lewis J, Raff M, Roberts K, Watson JD. In: Molecular Biology of the Cell. New York, Garland Publishing Inc., 1994.

31. Madara JL. Intestinal absorptive cell tight junctions are linked to cytoskeleton. Am J Physiol 1987; 253: C171175.

32. Gumbiner B. Structure, biochemistry and assembly of epithelial tight junctions. Am J Physiol 1987; 253: C749-758.

33. Schneeberger EE, Karnovsky MJ. Substructure of intercellular junctions in freeze-fractured alveolar-capillary membranes of mouse lung. Circ Res 1976; 38: 404-411.

34. Schneeberger EE. Heterogeneity of tight junction morphology in extrapulmonary and intrapulmonary airways of the rat. Anat Rec 1980; 198: 193-208.

35. Schneeberger EE, Lynch RD. Structure, function and regulation of cellular tight junctions. Am J Physiol 1992; 262: L647-L661.

36. Bershadsky AD, Vasiliev JM. Cytoskeleton. New York, Plenum Publishing Corp., 1988.

37. Ohishi I. Response of mouse intestinal loop to botulinum C2 toxin: enterotoxic activity induced by co-operation of nonlinked protein components. Infect Immun 1983; 40: 691-695. 